\title{
Technology as the Key Driver of Organizational Transformation in the eGovernment Period: Towards a New Formal Framework
}

\author{
Janja Nograšek and Mirko Vintar \\ University of Ljubljana, Faculty of Administration, Gosarjeva 5, 1000 Ljubljana, Slovenia \\ \{janja.nograsek, mirko.vintar\}@fu.uni-lj.si
}

\begin{abstract}
Relationship between technology and organisational changes in public sector has become the subject of increasingly intensive research within the last decade. Studies dealing such relationship could be divided in two major groups - first group regards ICT in the e-government period as the key factor of organizational transformation and the second group regards ICT as an equal and co-dependent element in relation to other organizational factors. These two groups of studies could be further classified within two organizational theories Technological Determinism and Socio-Technical Theory. The aim of this paper is to critically analyse those theories in the sense of formal theoretical framework to explain relationship between ICT and other organisational factors through the lens of Leavitt`s diamond. On the basis of critical analysis and synthesis of available literature the draft of a new conceptual model for explaining such relationship will be proposed.
\end{abstract}

Keywords: Technological determinism, Socio-technical theory, Leavitt`s diamond, Model representing the role of ICT in e-government period.

\section{Introduction}

For at least four decades, technology has gradually penetrated and influenced the operation of public sector organisations by changing and increasing its role with every new technological cycle. In the early stages, the influence was primarily visible in regard to the execution of administrative and technical as well as simpler professional tasks. During the later stages of intensive computerisation in particular during the egovernment period the influence of technologies upon the execution of processes rapidly increased, thereby causing them to become more standardised, formalised and more effective. The internet and related technologies caused a major leap forward in all spheres of operation of public sector organisations, namely in internal and external operations.

In parallel, to development of e-government the relationship between technology and organisational changes in the public sector has became the subject of increasingly intensive research and study. On the one hand a number of authors claim that information communication technologies (hereinafter referred to as ICT) in the egovernment period have the potential to create radical organisational changes 
(e.g. [3], [4], [13], [30], [32]). However, on the other hand there are also the authors who believe that ICT is only one of the elements within an organisation, which is reciprocally related to other elements within as well as outside of the organisation, and only appropriate connection between them enables optimum exploitation of the potentials of new technologies (e.g. [10], [22], [27], [38]).

Technology, as a factor in the development of organisations in the broadest sense has for almost a century been the subject of interest to numerous social sciences (political and organisational sciences in particular). In studying its influences upon various social systems, numerous "theories" have also been developed, which are used to formalise this relationship. For our further analysis we selected just the two of them: the Technological Determinism Theory on the one side and the SocioTechnical Theory on the other. ${ }^{1}$

Our initial assumption in this study has been that the development of e-government and its influence upon the organisational changes of government cannot sufficiently be placed into either of the above mentioned theories and models. On one side ICT is seen as the key factor of transformation of public sector organisations, however on the other side its influence more than ever depends upon other factors within an organisation.

The purpose of this paper is to follow the following three goals:

1. Critically analyse the above mentioned theories, particularly from the perspective of their applicability in the formal theoretical framework for explaining relationships between the increasingly intensive use of ICT in the government and technology related organisational changes.

2. Develop and introduce the draft of a new conceptual model for explaining the role and relationship between ICT and other key factors in an organisation for the successful development of e-government.

3. Examine the proposed model through analysis of the findings and statements of other authors, and define in more detail its features.

Chapter 2 introduces theoretical aspects regarding the role of technologies in changing organisations, analyses selected conceptual models and theories and examines their applicability towards explaining relationships between the development of e-government and related organizational transformations. Chapter 3 introduces the draft of a new conceptual model, a more detailed definition of its features and its evaluation. That is followed by the concluding chapter.

\section{Theoretical Aspects Regarding the Role of Technologies in Changing Public Sector Organisations}

As a theoretical starting point for understanding the role of technologies in changing organisations, Leavitt's definition of organisation will be used, which is best illustrated by the well known Leavitt's Diamond [23]. For an in-depth analysis of the relationship between technology and the changes to fundamental institutional

\footnotetext{
${ }^{1}$ However, one of the theories that would be worth mentioned at that point is also Structuration Theory proposed by Orlikowski; however this paper focused on first two theories.
} 
structures, we selected and examined two known theories appropriate for our discussion - Technological Determinism Theory and the Socio-Technical Theory.

\subsection{Leavitt's Extended Model}

One of the rather old and most recognised conceptual views regarding organisations is represented by Leavitt's Diamond (1964), which illustrates an organisation as a system of four entities - people, structure, tasks, and technology - and is frequently used as the basis for analysing the influence of technologies upon changes in organisations (e.g. [8], [26]). Later, the model was extended by other authors (e.g. [18]) and a fifth entity was added: organisational culture (Fig 1). These key elements of organisation are interdependent, which means that changes in one of them cause changes in the other.

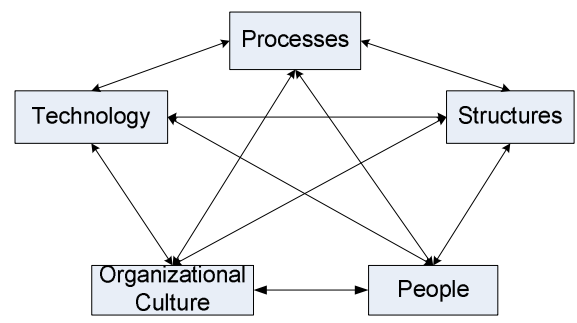

Fig. 1. Leavitt`s Extended Model (Source: Kovačič et al., 2004, p. 66)

\subsection{Technological Determinism}

Technological determinism is a reductionist theory that presumes that the technological process defines the social progress. Technological determinism regards technology as the basis of society in the past, present and future. New technologies transform society on all levels: institutional, social and on the individual level [6]. However, such a definition contains the view, which assumes that technology is more or less independent from social matters. Here we speak of so-called hard determinism. On the other side, soft determinism appeared as a response to the strict principles of hard determinism, and it emphasises the increased roles of inclusion and selection by an individual. According to this softer view, technology is placed within complex social, economic, political and cultural networks [20]. Even within soft determinism, technology is still the leading factor of social development, but it allows for an individual to adopt a decision regarding the predicted outcomes of a specific situation. It is interesting that within social science research dealing with modern technologies such as the internet, we are witnessing the appearance of tendencies towards explaining the relationship between technology and society in a relatively deterministic manner (see [7]). If we place technological determinism within the context of the organisation, the technology in an organisation is the factor that directs the transformation of organisations and their elements. 


\subsection{Socio-Technical Theory}

Socio-Technical Theory developed in the mid 20th century when researchers examining the impact of technologies on business efficacy and productivity came across some cases where employees resisted the introduction of new technologies through not achieving expected results and so on. Therefore, supported by sociological, psychological and anthropological sciences, the researchers established that the solution to such problems lies in combining the technological and sociological system.

Socio-Technical Theory regards an organisation as a socio-technical system built from two correlated systems - social and technical. The technical system is composed of the processes, tasks and technologies needed to transform input into output, whereas the social system is composed of people (their believes, skills, values, knowledge, needs), the relationships between them, remuneration systems and authority structures [5]. Every (trans)formation of an organisation as a system must consider these two sub-systems. A return to the classic socio-technical principles provides an environment for successful organisational changes following the implementation of new technologies [2], [5]. As can be seen from Fig 1, Leavitt's view of organisation and Socio-Technical Theory is heavily intertwined, which makes Leavitt one of the founders of this theory.

\subsection{Critical Analysis of Technological Determinism}

In accordance with technological determinism, technology directs the transformation of public sector organisations, which means that technology or its potential cause changes in processes, structure, people and organisational culture. These elements are separate and all they allow is a free choice regarding the use of potentials, which are enabled by modern ICT. In this case, technology is an independent variable, whereas processes, structures, people and culture are dependent variables (Fig 2). In that sense, ICT in e-government period is seen as a tool for the reform of bureaucracy. Jain e.g. [15] analyses e-government from two perspectives using the objective of Weber's bureaucratic model; first, as a tool for the "reform" of bureaucracy and second, that unsuccessful implementation of e-government is a result of bureaucracy. Egovernment as a tool of bureaucracy is also defined by the OECD [31], which claims that e-government is a key factor in the reform of government and that ICTs support this reform in many areas. Bellamy and Taylor [4] also justify such perspective by claiming that government can be transformed on the basis of technology, because information technology enables a new flow of information that endangers old norms and abilities.

However, some highly cited authors strongly oppose these "optimistic" perspectives regarding the reform potential of technology (e.g. [19]) and support their scepticism through numerous studies and empirical research that was conducted in 1980s and 1990s in the US. Furthermore, within the last decade, there emerge authors who establish that the transformational function of technology is not deterministic, because in practice equal inputs often give completely different results in various environments within the development of e-government (e. g. [36]). It can be said that the Theory of Technological Determinism is too one-dimensional and one-sided and 
does not provide enough formal framework for examining the influence of egovernment regarding organisational changes.

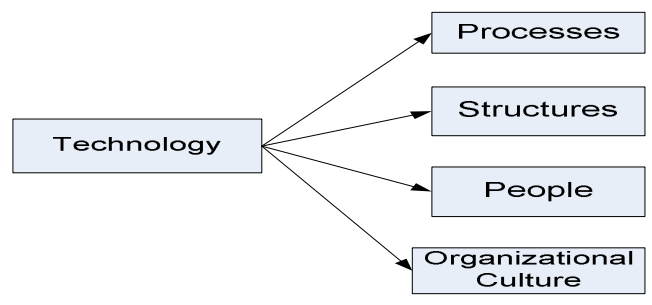

Fig. 2. Adjusted Leavitt`s Model Following Technological Determinism

\subsection{Leavitt's Model in the Context of Socio-Technical Theory}

Leavitt's model within the sphere of Socio-Technical Theory (see Fig 1) has already been introduced in the introduction to this chapter, because Leavitt [23] is one of the authors of this theory. In accordance with the Socio-Technical Theory, public sector organisations are systems of correlated elements that are interdependent, and changes in one of them cause changes in the other. In this case, technology is only one of the components of the socio-technical system, and as long as processes, people, cultures and structures remain at the level of bureaucracy, the potentials of modern technologies cannot be exploited. Van Wert [38] believes that the success of implementation of e-government is questionable, because officials want to own information and not share it and want their organisation to "shine" as opposed to others. On the basis of examining the implementation of e-public procurement in the local governments of Great Britain, Maniatopoulos [27] warns of the importance of organisational, political and economic factors, which influence the development and use of the technologies of e-government such as e-procurement. Another advocates of the socio-technical perspective is Fountain [10], who claims that ICT and organisational/institutional factors are reciprocally connected, that each of them may be a dependent and an independent variable, as each of them causes the other one.

\section{Towards Development of the New Formal Model}

ICT in e-government period is regarded by some authors as a tool for the radical transformation of public sector organisations and by others as merely one of the elements within an organisation that is equivalent to all of the other ones. Both author's groups arguments could be agree to some extent but not completely. The superficial overview of $\mathrm{I}(\mathrm{C}) \mathrm{T}$ 's role during various periods of the public sector's modernisation, as provided in the introduction, already leads to the establishment that its most powerful role has been played during the e-government period, constituting the greatest potential for transforming public sector organisations. This exact period of time is however facing the biggest challenge so far. No matter how high ICT's potential may be, no organisation can be transformed by it alone if it is not prepared, 
if it refuses to denounce the traditional, rigid sector and to form links within the organisation itself and among organisations, if it does not possess sufficient technical, system and process knowledge, if its managers refuse to take responsibility for change.

ICT's powerful role during the e-government period and its strong dependence on other elements within the organisation is precisely the reason which prevents both the social-technical and classical technological determinism theories from providing a satisfactory description and definition related to the transformation of organisations during the e-government period. That leads to the conclusion that a new model is needed that enables ICT to be placed into the centre of the socio-technical system as the key driver of organisational transformation. ICT as a central actor in such a model, however, cannot operate independently. An optimum potential utilisation is strongly co-dependent on the other elements of the model. This leads to the creation in some ways of a new conceptual model, which would provide the best description of the interdependent relationships among the key factors in the e-government period (Fig 3).

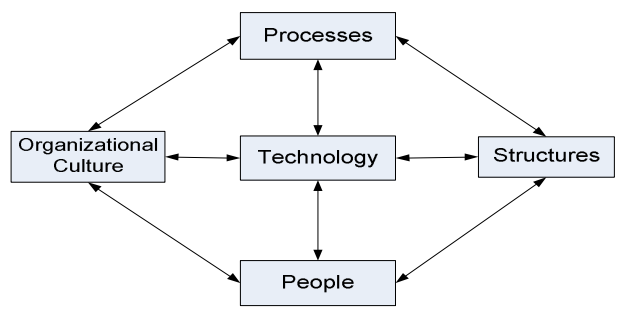

Fig. 3. Conceptual Model Representing the Role of ICT in the E-Government Period

\subsection{Primary Characteristics of the New Model}

Being recognized ICT is a key factor during the e-government period and holds great potential for transforming public sector organisations. New technologies enable horizontal and vertical process integration [21], simplified and significantly accelerated process execution, improved information management, more complex transactions, decreased staff burdening [14], [16] and improved public services [14], [17], [24]. They hold the potential for changing cultures, values and thinking [1].

These are only but a few of the potentials that new ICTs undoubtedly have and which impose their central role during the e-government period. They are, however, integrated into organisations that throughout the 20th century were dominated by Weber's bureaucracy model, based upon a strict top-down hierarchy. Modern ICT can be thus confronted with a whole array of factors which prevent organizations from fully benefiting from its potential. This raises the question of which changes should occur in the other elements of the organisation that those potentials could be exploited to the optimum level. Based on the review of existing studies in this field, where those changes have already been detected or highlighted, the extension of necessary changes in every given element of our proposed model is provided in Table 1. 
Table 1. Necessary changes to individual elements, which provide the most comprehensive utilisation of ICT's potential

\begin{tabular}{|c|c|c|}
\hline Element & Extent of changes & Authors \\
\hline Processes & $\begin{array}{l}\text { changes to the entire process } \\
\text { significantly accelerated process execution; } \\
\text { process can be executed } 24 / 7 \\
\text { horizontal and vertical process executions } \\
\text { changes to the rules, which determine the process } \\
\text { (trust, safety, maintenance and integrity) }\end{array}$ & $\begin{array}{l}\text { Layne \& Lee (2001) } \\
\text { Scholl (2003), Kim et al. } \\
(2007), \quad \text { Klievink \& } \\
\text { Janssen } \quad(2009), \quad \text { Politt } \\
(2010)\end{array}$ \\
\hline People & $\begin{array}{l}\text { employees have to gain new and complex skills } \\
\text { (e.g. self-organisation, confrontation with } \\
\text { unexpected tasks) and knowledge } \\
\text { leaders must be able to combine their ICT } \\
\text { knowledge and skills with their understanding of } \\
\text { the process dimension } \\
\text { leaders must be able to develop a strategic vision } \\
\text { and comprehensive human resource management, } \\
\text { project management and user-orientation strategies }\end{array}$ & $\begin{array}{l}\text { Layne \& Lee (2001), } \\
\text { Ho (2002), O’Donnell } \\
\text { et al. (2003), Griffin et } \\
\text { al. (2004), Leitner \& } \\
\text { Kreuzeder (2005), } \\
\text { Indihar Štemberger \& } \\
\text { Jaklič (2007) }\end{array}$ \\
\hline Culture & $\begin{array}{l}\text { transition to a service-oriented culture } \\
\text { the employees must overcome departmentalisation } \\
\text { thinking } \\
\text { employees must be encouraged to perform more } \\
\text { challenging tasks, to be willing to take } \\
\text { responsibility } \\
\text { inter-departmental and inter-organisational } \\
\text { cooperation and trust must be strengthened } \\
\text { the leaders' way of thinking must be radically } \\
\text { changed }\end{array}$ & $\begin{array}{l}\text { Ho (2002), O`Donnell } \\
\text { et al. (2003), Schedler \& } \\
\text { Schmidt (2004), Leitner } \\
\text { \& Kreuzeder (2005), } \\
\text { Kim et al. (2007) }\end{array}$ \\
\hline Structure & $\begin{array}{l}\text { on one hand, due to the horizontal and vertical } \\
\text { integration, tasks are undergoing a de- } \\
\text { specialisation process, while on the other hand, a } \\
\text { new task-structuring is required } \\
\text { Data digitalisation must be standardised, } \\
\text { procedures being standardised for several } \\
\text { departments or organisations simultaneously } \\
\text { as procedures are simplified and informatised, the } \\
\text { level of formalisation is decreased, while, on the } \\
\text { other hand, a new procedure execution method } \\
\text { requires new record safety, trust, maintenance and } \\
\text { integrity rules } \\
\text { decisions on the introduction of e-government is } \\
\text { transferred to e-leaders, which appear both on the } \\
\text { top and the middle level, which leads to a } \\
\text { decentralised decision-making process } \\
\text { the hierarchical structure is transformed into a } \\
\text { network one }\end{array}$ & $\begin{array}{l}\text { Layne \& Lee (2001), } \\
\text { O'Donnell et al. (2003), } \\
\text { Scholl (2003), Griffin et } \\
\text { al. (2004), Leitner \& } \\
\text { Kreuzeder (2005), } \\
\text { Maniatopoulos (2005), } \\
\text { Kim et al. (2007), } \\
\text { Klievink \& Janssen } \\
\text { (2009), van Veenstra et } \\
\text { al. (2010) } \\
\end{array}$ \\
\hline
\end{tabular}

The text below provides an assessment of the suggested model's individual elements with illustrative examples from existing studies. 


\subsection{Model Evaluation}

In order to examine our assumptions regarding ICT's role and its great co-dependence with other key institutional elements and to support our proposed model some illustrative e-government examples will be presented below.

\section{ICT as the key factor}

According to OECD's report [30], the internet and related technologies hold great potential for transforming the structure and processes in administration. Vintar [39] links the application of electronic documents, e-business and internet in internal and external administration operations with the introduction of new systemic and organisational solutions as well as new management models. ICT introduction positively affects the development of public sector organisations by decreasing the number of hierarchical levels [29], [37], transforming a hierarchical structure into a network one, decentralising activities and developing new horizontally integrated and strategically independent agencies [29]. Procedure standardisation would promote the creation of a network structure [37] and enable release of control [25].

\section{ICT and processes}

The processes themselves are most subjected to ICT's influences and potential. A rather significant number of authors reports about an increased process efficiency during the e-government period, mainly in terms of shortening the required time for executing a process [16], [28], [33], standardizing procedures [27], [33], [37] and facilitating and improving information management and exchange [14], but problems occur when a horizontal (integration among functions and services) and vertical (integration among organisations) process execution is required. In his analysis of U.S. municipal administrations, Moon [28] finds that most administrations have reached Level 1 or 2 in service development (one- or two-way interaction), but none have been able to reach Level 4, which requires vertical and horizontal integration. Groznik and Trkman [12] link the unsuccessful completion of the e-public procurement process in Slovenia to an inadequate regeneration of business processes for reasons of insufficient horizontal integration. Klievink and Janssen [17], in their analysis of progress towards joined-up government, which requires the integration among several organisations and departments, find that most Dutch public sector organisations have reached Level 2 - integrated organizations, but still have a lot of work to do until reaching Level 4 or 5 (inter-organisational integration and joined-up government).

\section{ICT and structures}

Non-utilisation of the potential for vertical and horizontal process execution is thus linked to the existing public sector organisation structure. Laynee and Lee [21], whose four-stage model of e-government transformation is based upon vertical and horizontal integration, highlighted that a management structure, based on specialisation, cannot be efficient during the e-government period. The tasks must be re-structured [35]. Based upon his analysis of the introduction of e-public procurements into the British local administration, Maniatopoulos [27] finds that the structural arrangement of local administrations is the main challenge of an e- 
procurement system implementation. Semi-autonomous units are based upon specialised services and are run by higher managers, intense rivalry and lack of cooperation. The change process is thus strongly affected by traditional structures. Li [25] finds that, despite large investments into technology, at the point of introducing e-government into the Chinese public administration, its structure remained essentially bureaucratic. The main challenge is thus how to apply this technology for achieving changes of the organisational structure towards an improved decentralisation and decreased formalisation.

\section{ICT and people}

Closed and inflexible structures can certainly be subscribed to a great extent to the organisation's management, which is held responsible by many authors for the nonutilisation of ICT's potential. Elnaghi et al. [9] place emphasis upon the role of leading figures in an organisation as the key actors for a successful e-government implementation; they point out that lack of authority is the main obstacle towards the development of e-government, which is regarded by leaders as a technological mission and not as a strategic vision. A lack of project management is one of the main reasons for the rather unsuccessful implementation of e-procurement in Slovenia [12]. Similarly, Klievink and Janssen [17], through analysing the progress toward a joinedup Dutch government, where most organisations can be found on the starting levels, found that project management and leaders play an ever-increasing role in achieving higher levels. A successful introduction of e-government requires interdisciplinary approaches and leaders who are able to combine their ICT knowledge with their understanding of the process dimension [11].

Inadequate staff competences also greatly hinder the utilisation of ICT's potential. The employee must be conscious of the fact that he/she is becoming the supervisor of the entire process and that he/she is not merely the person performing a task [21]. Moon [28] suggests that the biggest obstacle in the process of introducing egovernment initiatives into US municipal administrations is the lack of staff technical knowledge and the lack of technical staff members.

\section{ICT and organisational culture}

The staff is also closely linked to the organisational culture, which is regarded by some as the main culprit for poor utilisation of ICT. Maniatopoulos [27] thinks that the greatest challenge in introducing new technologies is the dominant organisational culture, which requires a different way of thinking. He reports that introducing XML standards into e-procurement procedures, organisations did not show great enthusiasm for the introduction of such structures and that employee still tend to execute the procedure manually. Also Klievink and Janssen [17] saw changes in culture as one of the conditions for successful transition to higher levels of joined-up government.

The illustrative examples presented above show rather clearly that ICT on one hand holds the potential for radical transformation of public sector organisations, while on the other hand show that the utilisation of its potential is more than ever dependent upon the willingness of other organizational elements to accept it. The examples also clearly show that authors, who analyse the non-utilisation of ICT's potentials, find obstacles for that not only from one but from more factors. That indicates a great level of co-dependence among those factors as well as that an 
optimal introduction and utilisation of ICT's potentials requires a comprehensive multi-dimensional approach.

\section{Conclusion}

By confronting two recognised theories in the field of social sciences - technological determinism and socio-technical theory and by defining a new model - this paper attempts to introduce a new perspective regarding the discussed problem and to contribute to further examination and a stronger integration of the relationship between ICT and organisational changes during the e-government period. As some research have already shown, ICT plays a more important role during the egovernment period than ever before, while at the same time its inter-dependence upon other elements in the organisations must form stronger links than ever before in order to provide for the maximum realization of the ICT's potentials. New relationships and dependencies among the main factors of successful e-government development, attempted to be formalised through the suggested model, are on the verge of being developed. A successful implementation of the model in practice requires a strategic approach towards the development and transformation of public sector organisations.

At the same time, there must be acknowledged the limits and weaknesses of the suggested model, because a successful introduction of e-government and required execution of organisational changes in public sector organisations are not only affected by elements within organisations, but also by external factors such as the political will for change, financial resources, elimination of distrust towards new technologies, legal obstacles, user demands, etc. This model should be supplemented further with external factors, which are extremely specific in the public sector and cannot be directly compared to private sector organizations.

\section{References}

1. Al-Shehry, A., Rogerson, S., Fairweather, N.B., Prior, M.: The Motivations for Change Towards E-Government Adoption: Case Studies from Saudi Arabia. In: eGovernment Workshop, eGov 2006 (2006)

2. Appelbaum, S.: Socio-technical systems theory: an intervention strategy for organizational development. Management Decision 35(6), 452-463 (1997)

3. Bekkers, V.: E-government and the emergence of virtual organizations in the public sector. Information Polity 8(3/4), 89-102 (2003)

4. Bellamy, C., Taylor, J.: Governing in the Information Age. Open University Press, Buckingham (1998)

5. Bostrom, R., Heinen, J.: MIS Problems and Failures: A Socio-Technical Perspective. MIS Quarterly 1(3), 17-32 (1997)

6. Chandler, D.: Technological or Media Determinism. Computed-Mediated Communication Magazine (1996)

7. Daly, J.: Studying the impacts of the Internet without assuming technological determinism. Aslib Proceedings 52(8), 285-300 (2000)

8. Danziger, J.N., Kraemer, K.L., Dunkle, D.E., King, J.L.: Enhancing the Quality of Computing Service: Technology, Structure, and People. Public Administration Review 53(2), 161-169 (1993) 
9. Elnaghi, M., Alshawi, S., Missi, F.: A Leadership Model for e-Government Transformation. In: Proceedings of European and Mediterranean Conference on Information Systems 2007, pp. 1-12 (2007)

10. Fountain, J.: Building the virtual state. Information technology and institutional change, Washington D.C (2001)

11. Griffin, D., Foster, A., Halpin, E.: Joined-up E-government: an exploratory study of UK local government progress. Journal of Information Science and Technology 1(2), 58-83 (2004)

12. Groznik, A., Trkman, P.: Upstream supply chain management in e-government: The case of Slovenia. Government Information Quarterly 26, 459-467 (2009)

13. Ho, A.T.-K.: Reinventing Local Governments and the E-Government Initiative. Public Administration Review 62(4), 434-444 (2002)

14. Indihar Štemberger, M., Jaklič, J.: Towards E-government by business process change - A methodology for public sector. International Journal of Information Management 27, 221$232(2007)$

15. Jain, A.: Using the lens of Max Weber's Theory of Bureaucracy to examine E-Government Research. In: 37th Hawaii International Conference on System Sciences, pp. 1-10 (2004)

16. Kim, H.J., Pan, G., Pan, S.L.: Managing IT-enabled transformation in the pubic sector: A case study on e-government in South Korea. Government Information Quarterly 24, 338 352 (2007)

17. Klievink, B., Janssen, M.: Realizing joined-up government - Dynamic capabilities and stage models for transformation. Government Information Quarterly 26, 275-284 (2009)

18. Kovačič, A., Jaklič, J., Indihar Štemberger, M., Groznik, A.: Prenova in informatizacija poslovanja. Ekonomska fakulteta, Ljubljana (2004)

19. Kraemer, K.L., King, J.L.: Information Technology and Administrative Reform: Will EGovernment Be Different? IJEGR - Final.doc, 1-18 (2005)

20. Lawson, C.: Technology, Technological Determinism and the Transformational Model of Technical Activity. Rough Draft, 1-24 (July 16, 2004)

21. Layne, K., Lee, J.: Developing fully functional E-government: A four stage model. Government Information Quarterly 18, 122-136 (2001)

22. Lazer, D.: How to Maintain Innovation.gov in a Networked World? In: Digital Government Workshop at the Kennedy School of Government. Harvard University, Cambridge (2002)

23. Leavitt, H.J.: Applied organization change in industry: structural, technical, and human approaches. In: Cooper, S., Leavitt, H.J., Shelly, K. (eds.) New Perspectives in Organizational Research, pp. 55-71. Wiley, Chichester (1964)

24. Leitner, C., Kreuzeder, M.: Organisational Changes, Skills and the Role of Leadership Required by eGovernment. In: Wimmer, M.A., Traunmüller, R., Grönlund, Å., Andersen, K.V. (eds.) EGOV 2005. LNCS, vol. 3591, pp. 210-217. Springer, Heidelberg (2005)

25. Li, Z.: How E-government affects the organisational structure in Chinese government. AI \& Soc. 23, 123-130 (2009)

26. Lucas, H.C., Baroudi, J.: The Role of Information Technology in Organization Design. Journal of Management Information Systems 10(4), 9-23 (1994)

27. Maniatopoulos, G.: E-government Movements of Organizationall Change: A Social Shaping Approach. In: 4th International Critical Management Studies Conference, Judge Institute of Management, Cambridge (2005)

28. Moon, M.J.: The Evolution of E-Government among Municipalities: Rhetoric or Reality? Public Administration Review 62(4), 424-433 (2002)

29. O'Donnell, O., Boyle, R., Timonen, V.: Transformational aspects of E-government in Ireland: Issues to be addressed. Electronic Journal of e-Government 1(1), 23-32 (2003) 
30. OECD. E-Government: Analysis Framework and Methodology. Paris: OECD (2001)

31. OECD. Information Technology as an Instrument of Public Management Reform: A Study of Five OECD Countries, OECD Working Paper No. 99. Paris: OECD (1998)

32. Okot-Uma, R.: Electronic Governance: Reinventing Good Governance. World Bank (2003)

33. Pollitt, C.: Technological Change: a central yet neglected feature of public administration. NISPA10 (Version 30-04-2010). Ljubljana (2010)

34. Schedler, K., Schmidt, B.: Managing the e-government organization. International Public Management Review 5(1), 1-20 (2004)

35. Scholl, H.J.: E-government: A Special Case of ICT-enabled Business Process Change. In: Proceedings of the 36th Hawaii International Conference on System Sciences, pp. 1-12 (2003)

36. Scholl, H.J.: Organizational Transformation Through E-Government: Myth or Reality? In: Wimmer, M.A., Traunmüller, R., Grönlund, Å., Andersen, K.V. (eds.) EGOV 2005. LNCS, vol. 3591, pp. 1-11. Springer, Heidelberg (2005)

37. van Veenstra, A.F., Janssen, M., Tan, Y.-H.: Towards an Understanding of E-Government Induced Change - Drawing on Organization and Structuration Theories. In: Wimmer, M.A., Chappelet, J.-L., Janssen, M., Scholl, H.J. (eds.) EGOV 2010. LNCS, vol. 6228, pp. 1-12. Springer, Heidelberg (2010)

38. Van Wert, J.: Questions about E-Government. In: Digital Government Workshop at the Kennedy School of Government. Harvard University, Cambridge (2002)

39. Vintar, M.: E- uprava - Pogled pod lupino. In: Vintar, M., Grad. J. (eds.). E-uprava: izbrane razvojne perspektive. Fakulteta za upravo, Ljubljana (2004) 